$13^{\text {th }}$ International Conference on

\title{
Weld Heat Tented Area Induced Failure of Boiler Water Wall Tubes in Power Generation Plant
}

\author{
A. El-Batahgy ${ }^{*}$ and Y. Hewedy ${ }^{* *}$
}

\begin{abstract}
The subject boiler is a vertical type with a capacity of 2063 ton/hr steam. Its operating and design pressure are 2608psi (18MPa) and 2928psi (20.2MPa) respectively while maximum outlet operating temperature is $1008^{\circ} \mathrm{F}\left(542.2^{\circ} \mathrm{C}\right)$. Water wall tubes are seamless tubes made of SA 210 and SA 213 T2 steels with nominal outer diameter of 2.5-3.0" (63.5-76.2mm) and wall thickness of $0.25-0.313 "(6.35-7.95 \mathrm{~mm})$. After 77360 operating hours, some water wall tubes have experienced leakage. Leaked tubes were subjected to different non-destructive and destructive examinations to clarify cause of failure.
\end{abstract}

Visual investigation showed through-thickness hole in base metal, close to weld region of two leaked tubes. Optical and scanning electron microscopic examinations of leaked zones disclosed complete decomposition of pearlite into ferrite and spheroidal carbides, creep voids, and grain boundary micro-cracking.

It is concluded that failure of the subject boiler tubes is attributed mainly to long term localized overheating. This could be related to heat tinted area (oxidation) formed on tube outer surface by heating (arc strike) during welding. During operation, oxidized or scale layer formed on outer surface of heat-tinted area will be exfoliated due to thermal stresses. Repeated cycles of thermal oxidation and exfoliation of scale layer will result in localized thinning and subsequently, localized overheating leading to acceleration of microstructure degradation. Thinning of water wall-tubes together with its microstructure degradation will result in increase in boiler pressure above the maximum safe working pressure leading to complete failure or leakage of tubes.

It was recommended that boiler water wall tubes to be checked using different nondestructive methods during the nearest shut down and all thinned zones of tubes to be replaced. In order to decrease the possibility of such failure in future, proper welding procedure should be applied so that heat-tinted areas due to heating or arc strike on tube outer surface to be avoided.

Keywords: weld heat tinted area, thermal stresses, localized thinning, long-term localized overheating, microstructure degradation, proper welding procedure.

\footnotetext{
* Prof. Dr. Eng., Head of Manufacturing Technology Department, Central Metallurgical Research and Development Institute, Cairo, elbatahgy@yahoo.com

** General Manager of Boilers, El-Kuriemat Power Generation Plant
} 
Paper: ASAT-13-MS-21

\section{Introduction}

The subject boiler is a vertical type with a capacity of 2063 ton/hr. It has been set into operation at El-Kuriemat power plant I since November 1997. The operating pressure of the boiler is 2608psi (18MPa) while its design pressure is 2928psi (20.2MPa) and maximum outlet operating temperature is $1008^{\circ} \mathrm{F}\left(542.2^{\circ} \mathrm{C}\right)$.

Boiler' water wall tubes include both rear wall and division wall seamless tubes. The nominal outer diameter and wall thickness of rear wall tubes are $2.5 "(63.5 \mathrm{~mm})$ and $0.25 "(6.35 \mathrm{~mm})$ respectively. Division wall tubes are reducer tubes with nominal outer diameters and wall thicknesses of 2.5-3.0" $(63.5-76.2 \mathrm{~mm})$ and $0.25-0.313^{\prime \prime}(6.35-7.95 \mathrm{~mm})$ respectively. The boiler' seamless water wall tubes were made of medium carbon steel SA 210 and low alloy steel SA 213 T2 (ASME Code).

After 77360 operating hours, some water wall tubes have experienced leakage just below the firing zone of the boiler. Visual inspection indicated that leakage took place in base metal, not in circumferential welds of tubes. Twenty two tubes samples with $1000 \mathrm{~mm}$ length from leaked region that included 13 rear water wall tubes and 9 division water wall tubes were cut, removed and subjected to detailed investigation for failure analysis. Figure 1 shows schematic illustration of location and configuration of failed water wall tubes.

\section{Non-Destructive Investigations}

The failed water wall tubes samples were carefully examined before sectioning it for destructive investigations. General and close up views from different sides of failed rear water wall tubes are shown in Fig. 2. One important notice is the through-thickness hole of tube 4 (Fig. 2-c) and the through-thickness rupture of tubes 8 and 9 (Fig. 2-d). Another notice is the external damage of other tubes where metal was removed from outer surface. It seems that external damage or reduction in tube wall thickness from outer surface was occurred by mechanical action after leakage took place. It is observed that through-thickness hole where leakage occurred in case of tube 4 is confined to localized thinned zone close to weld region. Generally, tube failure is outward (failure direction is from inside toward outside) and characterized by a thin edge. No bulges were observed at either failed or non-failed tubes. Both dye penetrant and magnetic particles examinations of rear water wall tubes revealed no surface cracks around either failed or non-failed zones.

Failed rear water wall tubes were split longitudinally around its leaked zone where its inner surface was carefully investigated. Enlarged views of inner surface and cross section of leaked zone of tube 4 are shown in Fig. 3. It is obvious that no internal damage was occurred around leaked zone. Localized thinning is confined to outer surface of leaked zone. Enlarged views of cross sections of leaked tubes 8 and 9 are shown in Fig. 4. One important notice is the localized thinning as a result of metal removed from outer surface. It can be noticed also that leakage or rupture is confined to localized thinned zone. Except through-thickness rupture, no internal damage was occurred. Localized thinning of tubes around leaked zones has been confirmed by thickness measurements using UT-thickness meter. Results of thickness measurements indicated that wall thickness was reduced from $6.5 \mathrm{~mm}$ to about $3.1 \mathrm{~mm}$ around leaked zones. 


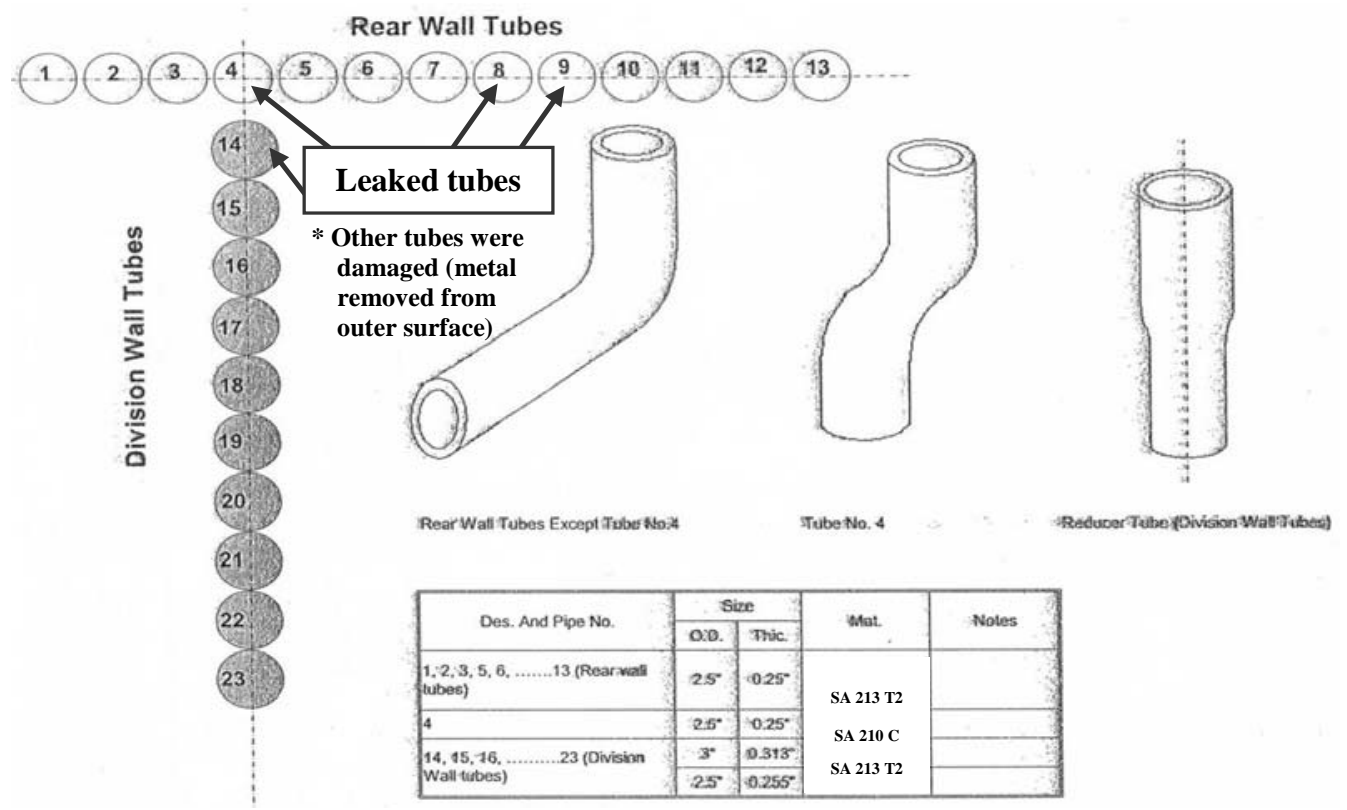

Fig. 1 Schematic illustration of location and configuration of failed rear and division water wall tubes of the boiler.

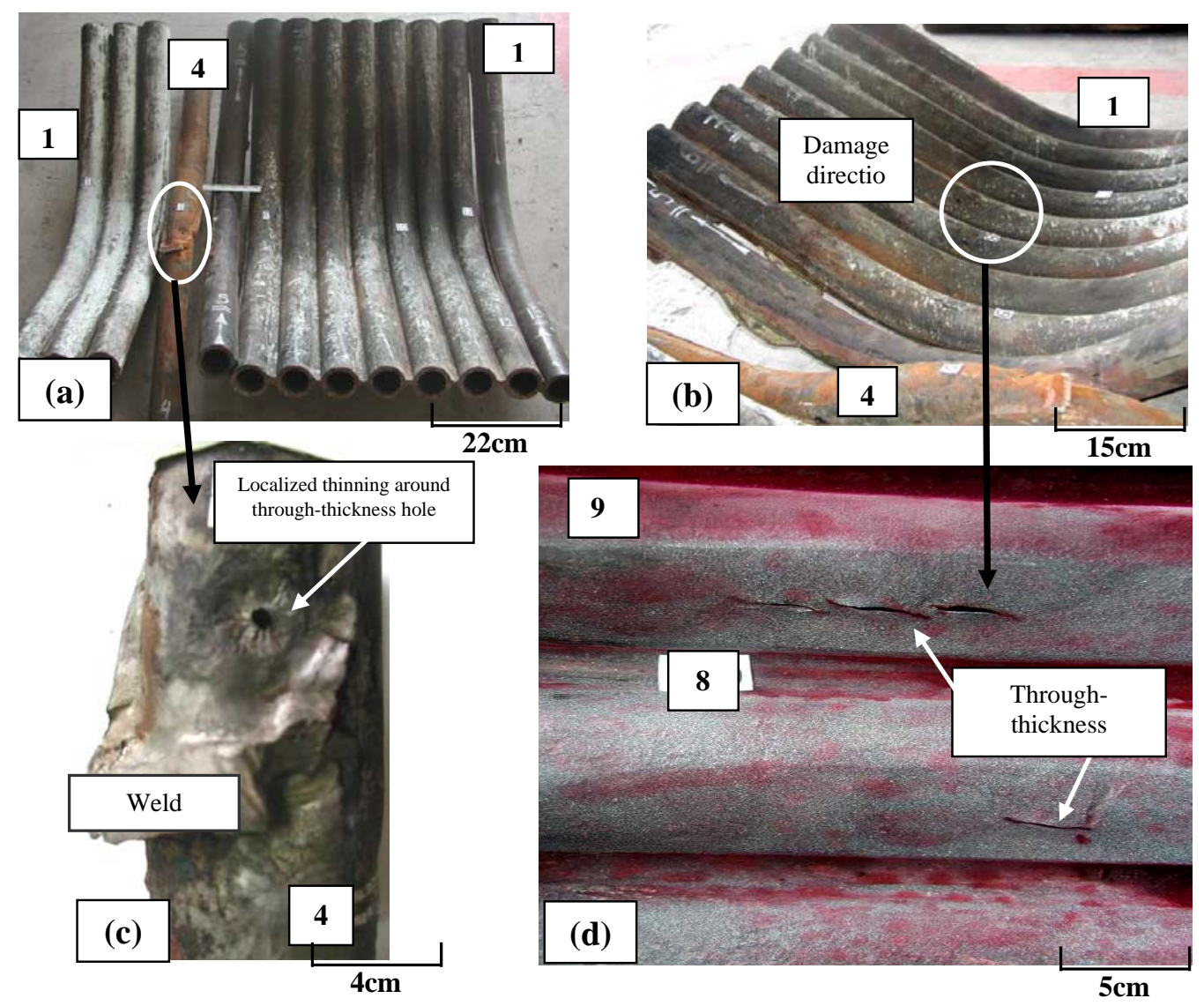

Fig. 2 General (a, b) and close up (c, d) views of failed rear water wall tubes showing through thickness hole close to weld region of tube 4 and through-thickness rupture at externally damaged (thinned) zone of tubes 8 and 9. 


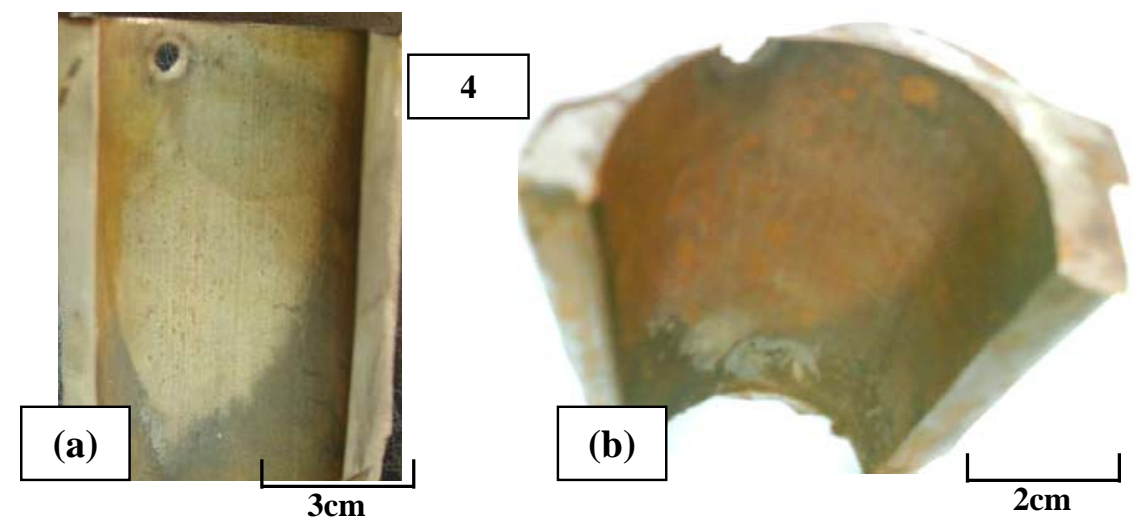

Fig. 3 Photographs of inner surface (a) and cross section (b) of leaked zone of tube 4 showing no internal damage around leaked zone. Localized thinning is confined to outer surface of leaked zone.

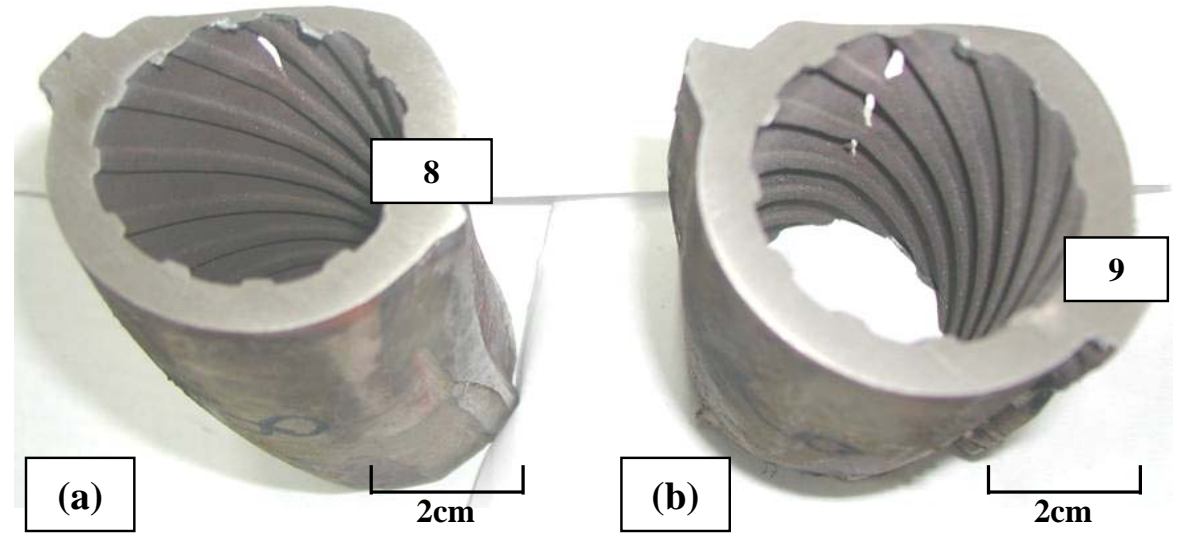

Fig. 4 Cross sections of ruptured zone of rear water wall tubes 8 and 9. Except through-thickness rupture at localized thinned zone, no internal damage occurred. Localized thinning is related to metal removed from outer surface.

General and close up views of failed division water wall tubes are shown in Fig. 5. The most important notice is the through-thickness hole of tube 14. Note external damage of other tubes where metal was removed from outer surface. It seems that such external damage or reduction in wall thickness is related to metal removed from outer surface by mechanical action after leakage took place. It should be reported also that localized thinning where leakage was occurred in case of tube 14 is close to weld region. Dye penetrant and magnetic particles inspections of failed division water wall tubes showed no surface cracks around either leaked or non-leaked zones.

Failed division water wall tubes were split longitudinally where its inner surface was carefully investigated. Enlarged views of inner surface and cross section of leaked zone of tube 14 are shown in Fig. 6. No internal damage was observed around leaked zone. Localized thinning is confined to outer surface of leaked zone. In other words, localized thinning was occurred as a result of metal removed from outer surface. Except through-thickness hole where leakage occurred, no internal damage was observed. Localized thinning of tubes around leaked zones has been confirmed by thickness measurements using UT-thickness meter. Results indicated that wall thickness was reduced from $7.2 \mathrm{~mm}$ to about $3.3 \mathrm{~mm}$ around leaked zone. 


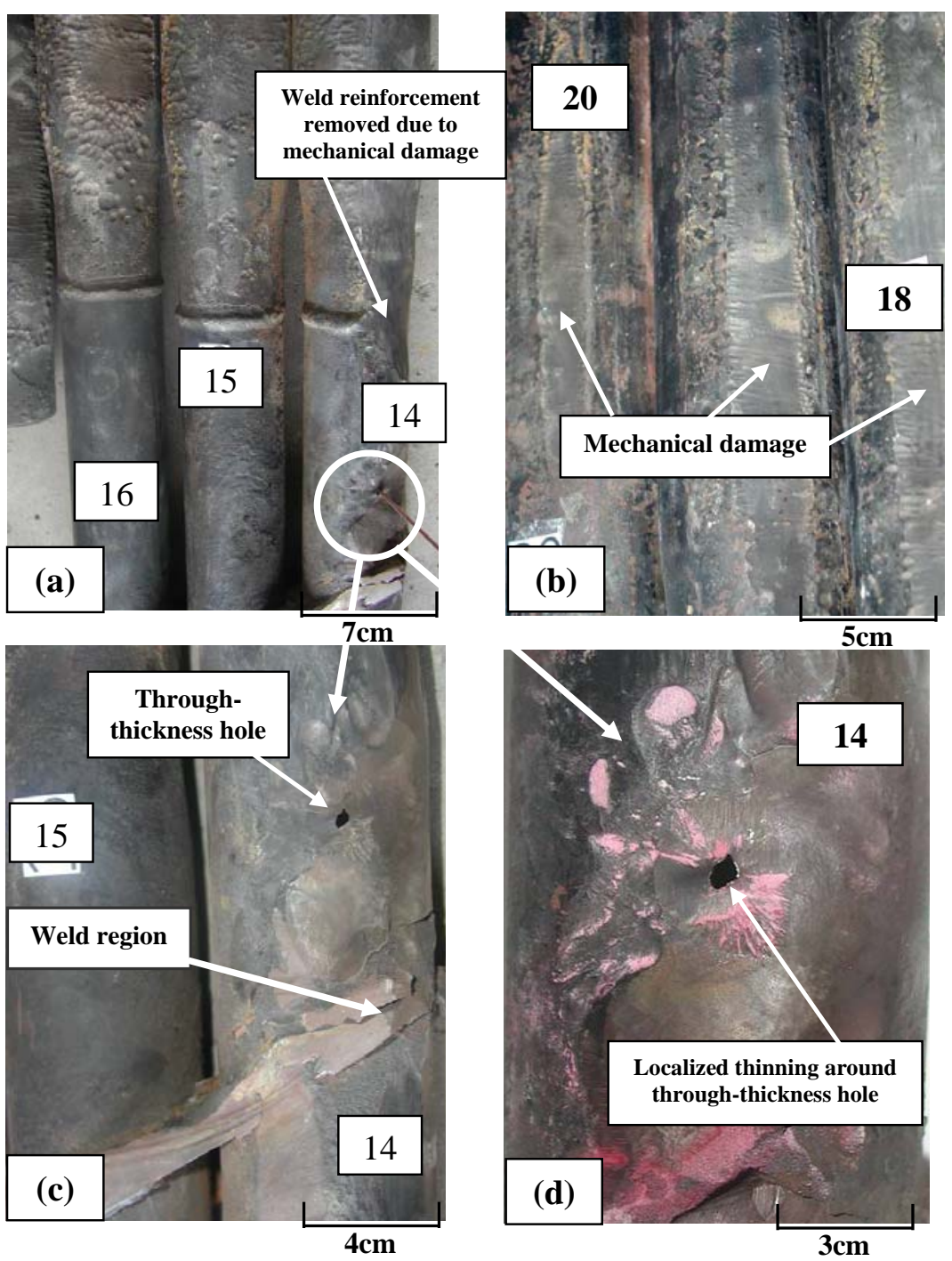

Fig. 5 Photographs of failed division water wall tubes showing through-thickness hole close to weld region of tube 14 . Note mechanical damage of other tubes where metal was removed from outer surface. Dye penetrant investigation disclosed no surface cracking.

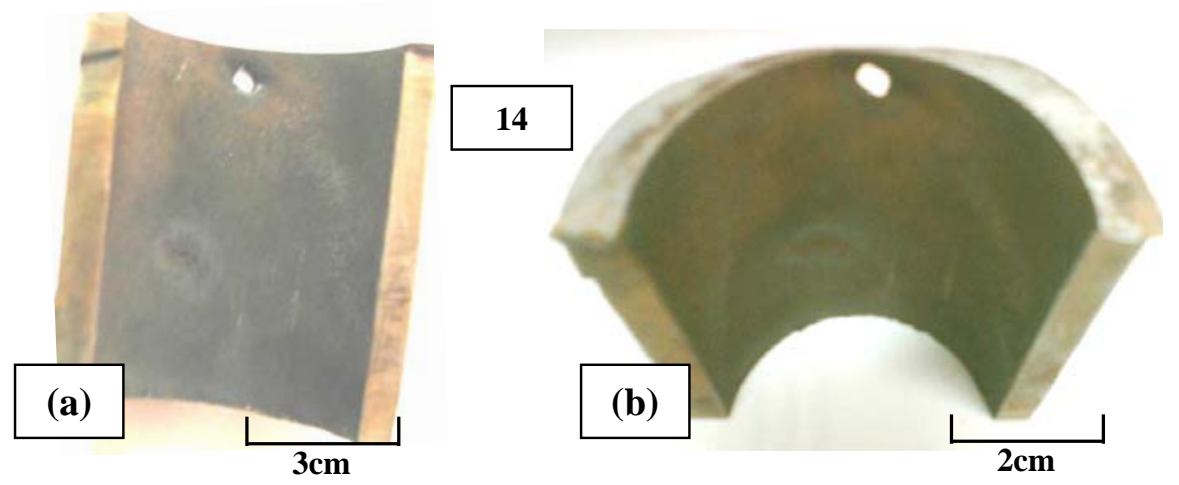

Fig. 6 Photographs of inner surface (a) and cross section (b) of leaked zone of division water wall tube 14 showing no internal damage around leaked zone. Note localized thinning on outer surface of leaked zone. 


\section{Destructive Examinations}

Specimens from leaked and non-leaked zones were cut out and prepared for chemical analysis, optical and scanning electron microscopic examinations, hardness measurements, and tensile test. Results of chemical analysis indicated that chemical composition of failed water wall tubes is conformed to the range specified for SA 213 T2 and SA 210 C steels based on boiler design.

Regarding metallographic examinations, high magnification optical microscopic photographs of cross sections taken from leaked and non-leaked zones of rear water wall tube 4 are shown in Fig. 7. Microstructure of leaked zone exhibited remarkable degradation where complete decomposition of pearlite into ferrite and spheroidal carbides is observed (Fig. 7-a). On the other hand, no considerable degradation in microstructure was occurred at non-leaked zone where almost normal ferritic-pearlitic structure is still existed (Fig. 7-b).

Optical micrographs of cross sections taken from leaked and non-leaked zones of division water wall tube 14 are shown in Fig. 8. The important notice is the complete decomposition of pearlite into ferrite and spheroidal carbides at leaked zone (Fig. 8-a) while almost normal ferritic-pearlitic structure is observed at non-leaked zone (Fig. 8-b).
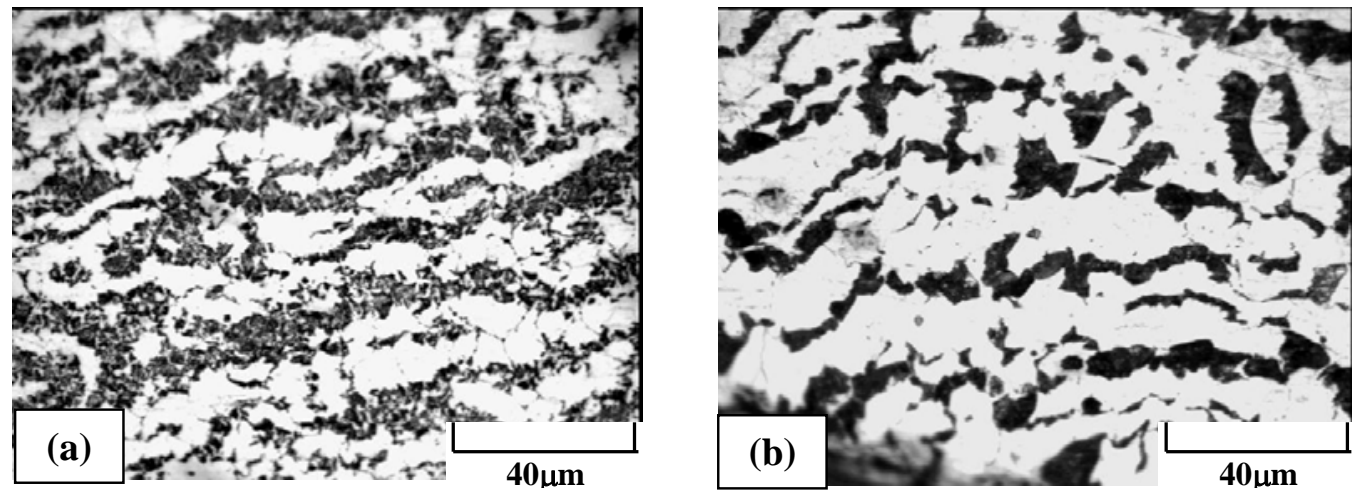

Fig. 7 Optical micrographs of cross sections taken from leaked (a) and nonleaked (b) zones of tube 4. Note complete decomposition of pearlite into ferrite and spheroidal carbides at only leaked zone.
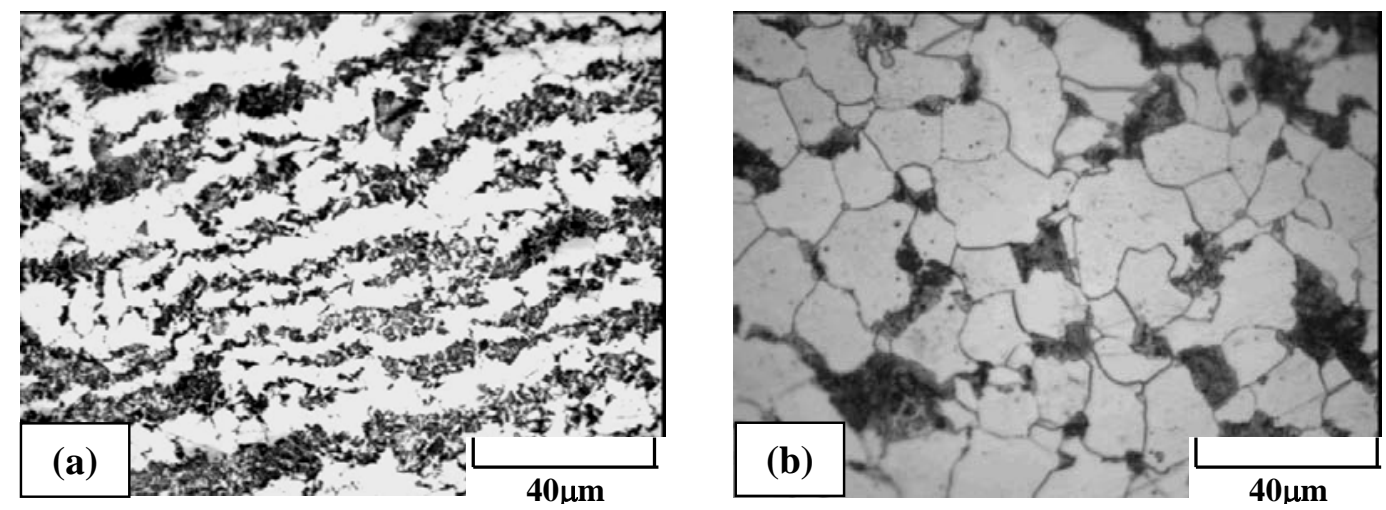

Fig. 8 Optical micrographs of cross sections taken from leaked (a) and nonleaked (b) zones of tube 14. Note complete decomposition of pearlite into ferrite and spheroidal carbides at only leaked zone. 
Optical micrographs with different magnifications of a cross section taken from ruptured or leaked zone of rear water wall tube 8 are shown in Fig. 9. One important notice is the occurrence of decarburization around main crack (Fig. 9-a). Higher magnification of decarburized zone disclosed formation of creep voids that means remarkable degradation of microstructure Fig. 9-b, c). It should be reported that optical microscopic investigation of cross sections taken from damaged or thinned but non-leaked zones showed deformed ferriticpearlitic structure with partial decomposition of pearlite into ferrite and spheroidal carbides.

Optical micrographs of cross sections taken from thinned and non-thinned zones of nonleaked tube 10 are shown in Fig. 10. It can be noticed that coarser ferritic pearlitic structure was observed at thinned zone (Fig. 10-a) in comparison with non-thinned zone (Fig. 10-b).

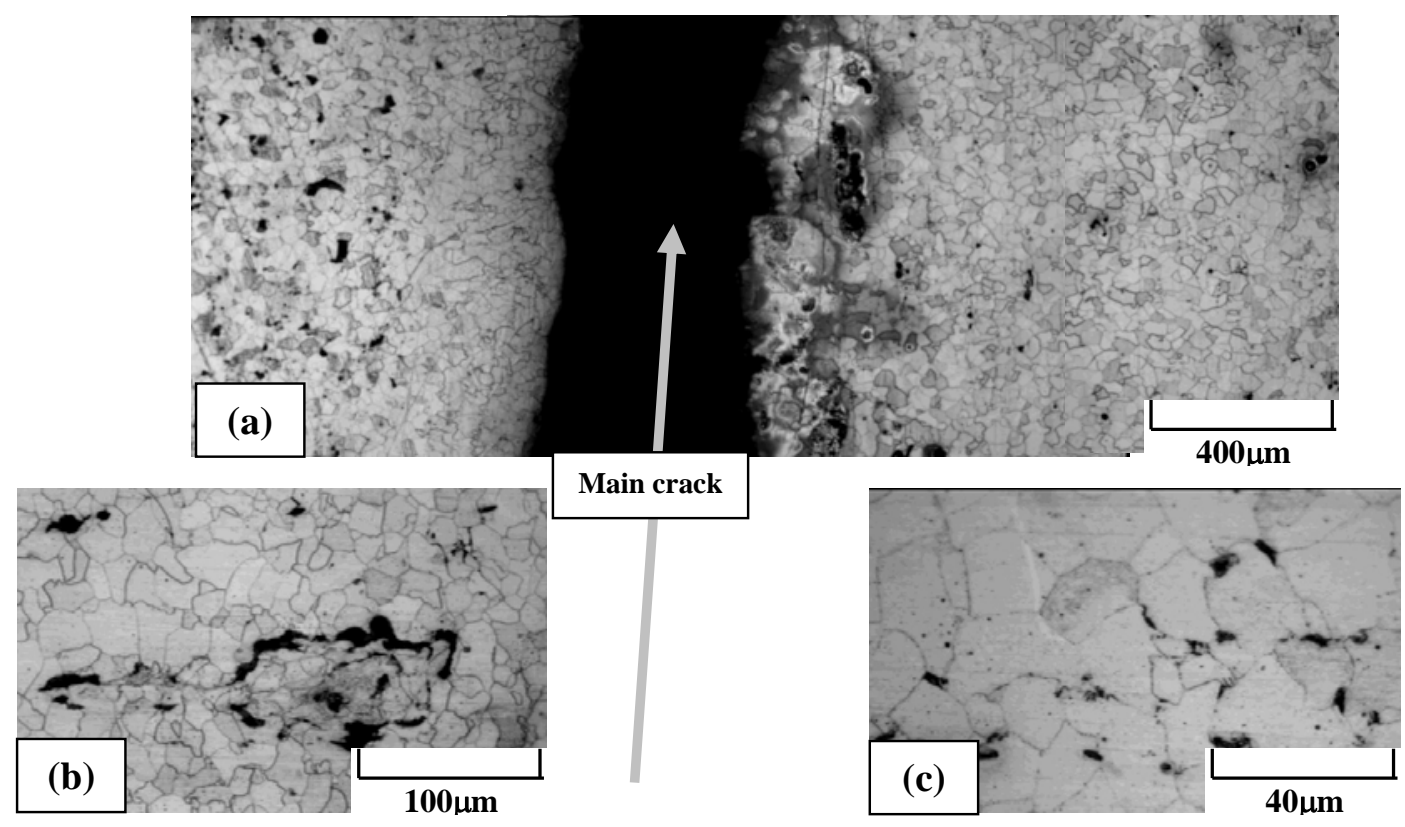

Fig. 9 Optical micrographs of ruptured zone of tube 8 showing decarburization and creep voids around main crack.
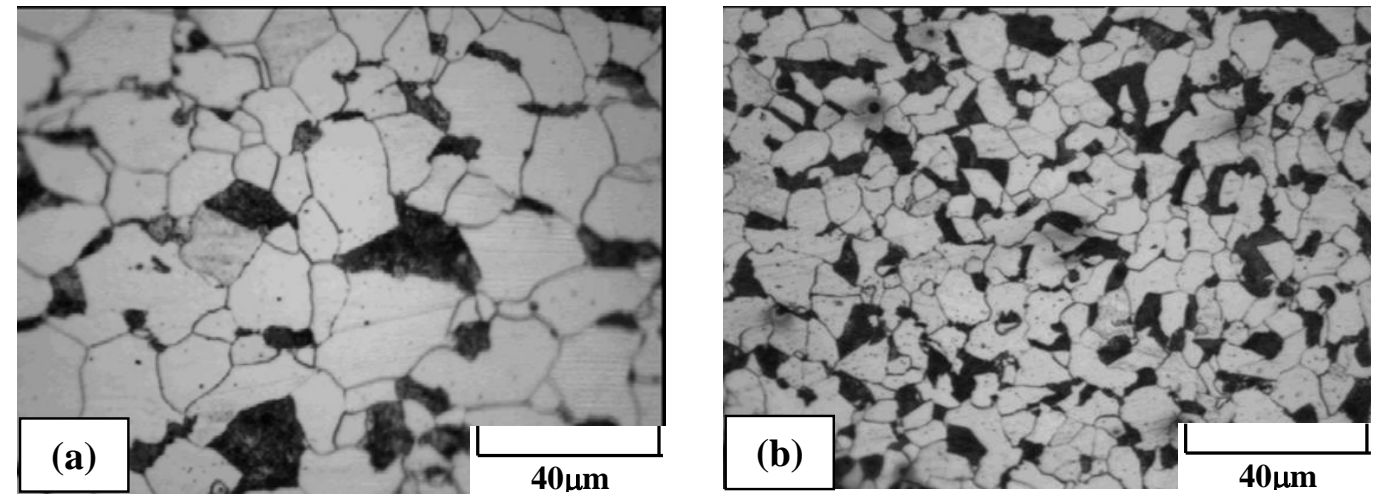

Fig. 10 Optical micrographs of cross sections taken from thinned (a) and nonthinned (b) zones of non-leaked tube 10 showing coarser ferritic pearlitic structure at thinned zone. 
In order to help in identification of failure mechanism, cross sections of leaked zones were examined using scanning electron microscope. Scanning electron micrographs of a cross section taken from leaked zone of rear water wall tube 4 are shown in Fig. 11 while those of a cross section taken from leaked zone of division water wall tube 14 are shown in Fig. 12 . Scanning electron microscopic investigation confirmed complete decomposition of pearlite into ferrite and spheroidal carbides, formation of creep voids and grain boundary microcracking.
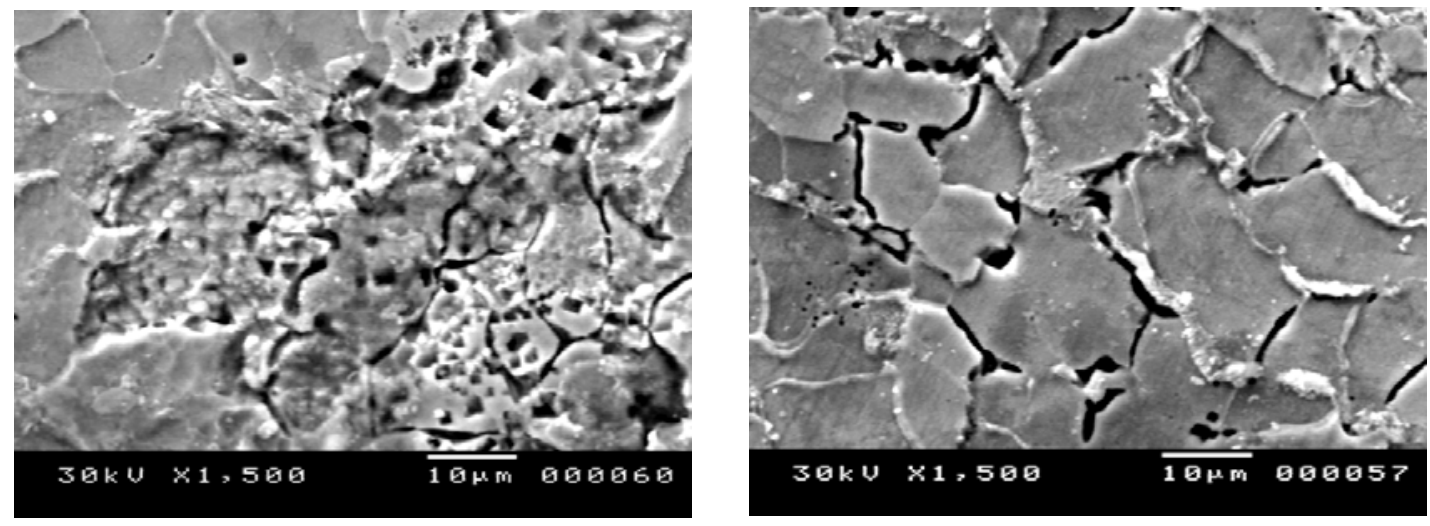

Fig. 11 Scanning electron micrographs of a cross section taken from leaked zone of rear water wall tube 4 confirming complete decomposition of pearlite into ferrite and spheroidal carbides, creep voids, and grain boundary micro-cracking.
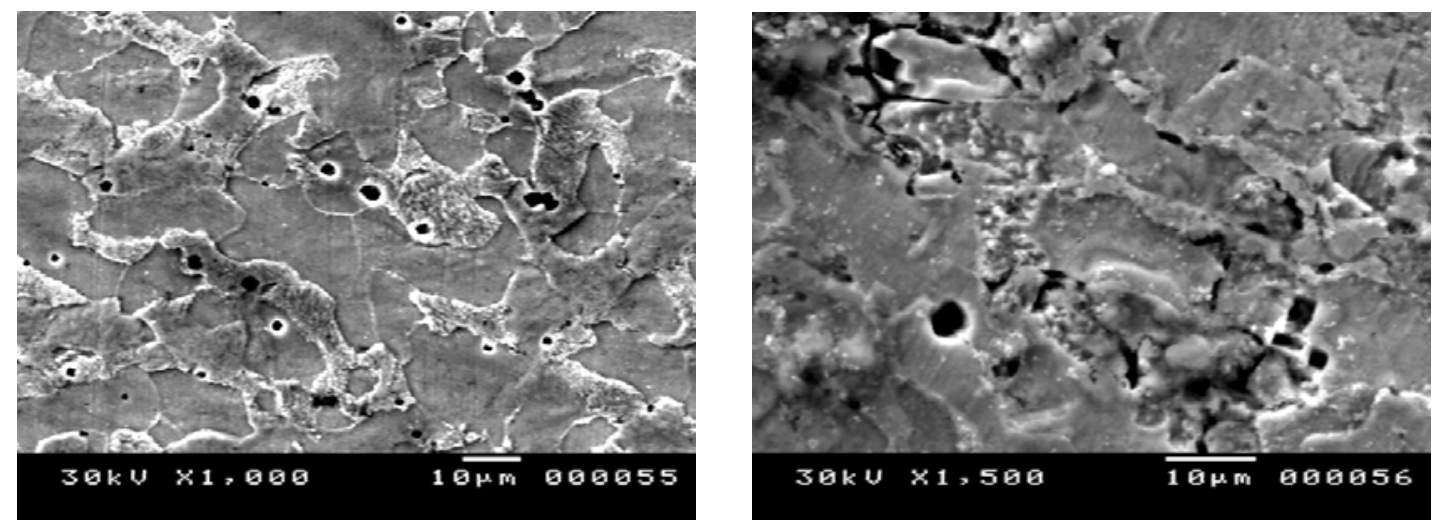

Fig. 12 Scanning electron micrographs of a cross section taken from leaked zone of division water wall tube 14 confirming complete decomposition of pearlite into ferrite and spheroidal carbides, creep voids, and grain boundary micro-cracking.

Survey of hardness measurements through tube wall thickness of leaked and non-leaked zones was carried out. Regarding rear water wall tubes, results indicated no considerable difference in hardness values of both outer and inner surfaces of tubes. However, average hardness value of leaked zone (144HV) is lower than that of non-leaked zone (157HV). For division water wall tubes, results indicated that hardness values of outer surface $(121 \mathrm{HV})$ of leaked tubes are lower than that of its inner surface $(141 \mathrm{HV})$. Also, average hardness value of leaked zone 
(134HV) is lower than that of non-leaked zone (152-177HV). The obtained hardness values are correlated to microstructures observed.

Results of tensile test indicated that both yield and tensile strength of used water wall tubes are conformed to the specified range for SA 213 T2 and SA 210 C steels. However, elongation of used tubes was decreased and this could be related to the occurred microstructure degradation.

\section{Discussion}

Visual investigation indicated localized thinning with through-thickness holes of tubes 4 and 14. It showed external damage of other tubes where metal was removed only from outer surface. It is noticed that localized thinning was occurred as a result of metal removed from only outer surface. It is observed also that leakage or through-thickness hole was confined only to localized thinned zone. Visual investigation showed no damage on inner surface of either leaked or non-leaked tubes. In other words, except through-thickness hole or rupture, no internal damage was occurred. However, visual investigation indicated that through thickness hole, where leakage was occurred in case of tubes 4 and 14 is close to weld region. .

Chemical analysis of the failed water wall tubes indicated that chemical composition of rear water wall tubes lies within the specified range for SA213 T2 steel while that of division water wall tubes including tube 4 lies within the specified range for SA $210 \mathrm{C}$ steel.

Optical microscopic examination of leaked zones exhibited decarburization at outer surface, complete decomposition of pearlite into ferrite and spheroidal carbides, creep voids and grain boundary cracking. This microstructure is different from that of non-leaked zone that exhibited no remarkable degradation where almost normal ferrite pearlite structure is still existed. Scanning electron microscopic investigation of leaked zone confirmed complete decomposition of pearlite into ferrite and spheroidal carbides, creep voids and intergranular cracking propagated through grain boundary voids.

These findings increase the possibility that failure of boiler water wall tubes is related mainly to long-term localized overheating. Decomposition of pearlite into ferrite and spheroidal carbides, which weakens tube material indicated that temperatures above the maximum operating temperature $542.2^{\circ} \mathrm{C}$ and below $\mathrm{A}_{\mathrm{C} 1}$ or $727{ }^{\circ} \mathrm{C}$ (the temperature at which austenite begins to form) were reached.

Localized overheating could be related to heat tinted area (oxidation) formed on tube outer surface by heating (arc strike) during welding that in turn reduced thickness. Existence of leaked zone close to weld region of tubes 4 and 14 support this opinion. During operation, oxidized or scale layer formed on outer surface of heat-tinted area will be exfoliated due to thermal stresses. Repeated cycles of thermal oxidation and exfoliation of scale layer formed on outer surface of heat-tinted area will result in localized thinning.

Thinning of water wall-tubes will result in increase in boiler pressure above the maximum safe working pressure that in turn and together with microstructure degradation (creep damage) will result in initiation of intergranular or grain boundary cracking leading finally to outward failure (direction of failure is from inside toward outside of tube). It is believed that this is what occurred in case of water wall tubes 4 and 14 where the observed thinning pattern on outer surface and outward fracture support this opinion. 
On the other hand, it is believed that localized thinning of other tubes including tubes 8 and 9 is related to mechanical damage (not thermal damage) after leakage of tubes 4 and 14 took place. In other words, water jet produced after failure of tubes 4 and 14 took place has resulted in metal removal (by mechanical action) from outer surface of surrounding tubes that in turn resulted in severe thinning and subsequently overheating that means microstructure degradation.

Severe thinning of tubes 8 and 9 together with microstructure degradation will result in increase in boiler pressure above the maximum safe working pressure that in turn will result in initiation of intergranular or grain boundary cracking leading finally to outward rupture.

\section{Conclusion and Recommendations}

Based on the above investigations it can be concluded that failure of the subject boiler water wall-tubes is attributed mainly to long term localized overheating. Long-term overheating is a condition in which metal temperatures exceed design limits for days, weeks, months, or longer. Because steel loses much strength at elevated temperatures, failure caused by normal internal pressure becomes more likely as temperatures rise. Long-term overheating is evident in case of tubes 4 and 14 from tube external thinning pattern, microstructure degradation or complete decomposition of pearlite phase into ferrite and spheroidal carbides, creep voids and grain boundary micro-cracking.

Localized overheating in case of tubes 4 and 14 could be related to heat tinted area (oxidation) formed on outer surface by heating (arc strike) during welding that in turn reduced thickness. Existence of leaked zone close to weld region of tubes 4 and 14 support this opinion. During operation, oxidized or scale layer formed on outer surface of heat-tinted area will be exfoliated due to thermal stresses. Repeated cycles of thermal oxidation and exfoliation of scale layer formed on outer surface of heat-tinted area will result in localized thinning.and subsequently overheating that means microstructure degradation.

Thinning of water wall-tubes together with its microstructure degradation (creep damage) will result in increase in boiler pressure above the maximum safe working pressure, which will cause intergranular or grain boundary cracking. Once a crack has started, the tip of the advancing crack has a small radius and attendant stress concentration is great that in turn accelerates propagation of crack leading finally to outward fracture. It is believed that this is what occurred in case of water wall tubes 4 and 14 where the observed thinning pattern on outer surface and outward fracture support this opinion.

On the other hands, it is believed that localized thinning of other tubes including tubes 8 and 9 is related to mechanical damage (not thermal damage) after failure of tubes 4 and 14 took place. In other words, water jet produced after failure of tubes 4 and 14 took place has resulted in metal removal (by mechanical action) from outer surface of surrounding tubes that in turn resulted in severe thinning.

Severe thinning of tubes 8 and 9 together with its microstructure degradation will result in increase in boiler pressure above the maximum safe working pressure that in turn will lead to initiation of intergranular or grain boundary cracking at tube inner surface (bottom of spiral teeth) leading finally to outward rupture. Again, the observed external thinning pattern together with outward rupture supports this opinion. 
In addition, cyclic and excessive thermal fluctuations could result in thermal fatigue damage. However, thermal fatigue damage is not the main failure mechanism. It could only help or accelerates fracture.

It was recommended that boiler tubes to be checked using different non-destructive methods including visual investigation and thickness measurements during the nearest shut down and all thinned zones to be replaced.

In order to decrease the possibility of such failure in future, proper welding procedure should be implemented. In other words, heat-tinted areas due to heating or arc strike on tube outer surface during welding should be avoided.

\section{Acknowledgment}

Authors are indebted to Prof. W. Metwally, Corrosion Laboratory, Central Metallurgical Research and Development Institute (CMRDI), for valuable discussion and contribution during conducting this work. Deep thanks are due to Eng. H. El-Behery, Sector Director, ElKuriemat Power Plant I, for support and encourage during conducting this work.

\section{References}

[1] R. D. Port and H. M. Herro, The NALCO Guide to Boiler Failure Analysis, McGrawHill, Inc, New York, 1991..

[2] R. D. Barer and B. F. Peters, Why Metals Fail, $6^{\text {th }}$ ed., Gordon and Breach Science Publishers, New York, 1991.

[3] ASM Handbook, Failure Analysis and Prevention, Vol. 11, Materials Park, OH: ASM International, 1996.

[4] V.J. Colangelo, F.A. Heiser, Analysis of Metallurgical Failures, 2nd. ed., New York, NY: Wiley, 1987.

[5] C. R. Brooks and A. Choudhury, Metallurgical Failure Analysis, McGraw-Hill, New York, 1993.

[6] C. R. Brooks and A. Choudhury, Failure Analysis of Engineering Materials, McGrawHill, New York, 2002.

[7] M.G. Fontana, Corrosion Engineering, $3^{\text {rd }}$ ed. (New York, NY: McGraw-Hill, 1987).

[8] A. El-Batahgy and W. Metwally. "Weld Defect and Design Induced Failure of Draught Fan of Boiler Flow Gases”, Al-Azhar Engineering Fifth International Conference, 19- 22 February 1997, Cairo

[9] A. El-Batahgy: "Catastrophic Failure of Waste Heat Boiler", Materials Performance Journal, February 1997.

[10] A. El-Batahgy "Weld Defect and Design Induced Failure of Draught Fan of Boiler Flow Gases”, Al-Azhar Engineering Fifth International Conference, 19-22 Feb. 1997, Cairo

[11] A. El-Batahgy and W. Metwaly, "Failure Analysis of Boiler Water Wall-Tubes at a Power Generation Plant”, $31^{\text {st }}$ Annual Convention of the International Metallographic Society, 26 - 29 July 1998, Ottawa, Canada

[12] A. El-Batahgy, M. Amin and G. Fathy: "Failure of a Column Reboiler in a MEG Recovery Unit”, Materials Performance Journal, August 2008. 